\title{
On Key Animation and Key Animator
}

\author{
Jie Gu \\ Arts College \\ Tianjin University of Technology and Education \\ Tianjin, China 300222
}

\begin{abstract}
Based on the understanding of key animation, this paper has analyzed the differences and relationsbetween key animation and animation. The author tries to figure out the requirements and qualities for being a great key animator on industry conditions. In this way, guiding the key animation beginners and helping them avoid making mistakes.
\end{abstract}

Keywords-key animation; animation; key animator; teamwork

\section{INTRODUCTION}

Because of its combined art form, animation is accepted and loved by more and more people and it is also becoming part of our lives.

The creation process and methods vary from different production companies, but the basic procedure is the same, which includes pre-animation, mid-animation and late period of animation. And key animation which can decide the quality of movie directly is the most important part of mid-animation. In this case, this paper focuses on talking about the cognition and understanding of key animation and the requirements and qualities for a good key animator. We hope this paper can offer some help to those who are working on key animation creations.

\section{UNDERSTANDING OF KEY ANIMATION}

Key animator is the creator of all characters in an animation. Those characters are the same as actors in the film acted by real people, who are the main parts of the director's creation. That is to say, the success of an animation depends on those characters in the animation.

It is the subjective feeling of a director to design a frame and to express it and it is also an artistic creation; this plays a decisive role in the performance of animation and expression of the scripts. However, only by the successful recreation of key animation can the animation be a success eventually. This means that the key animators should consider the creation intention of the director and the design of every character as well. They should also make paintings with characters of different actions and expressions under different environment.

Briefly speaking, key animation is the painting of dynamic moving objects. "Fig. 1", "Fig. 2"

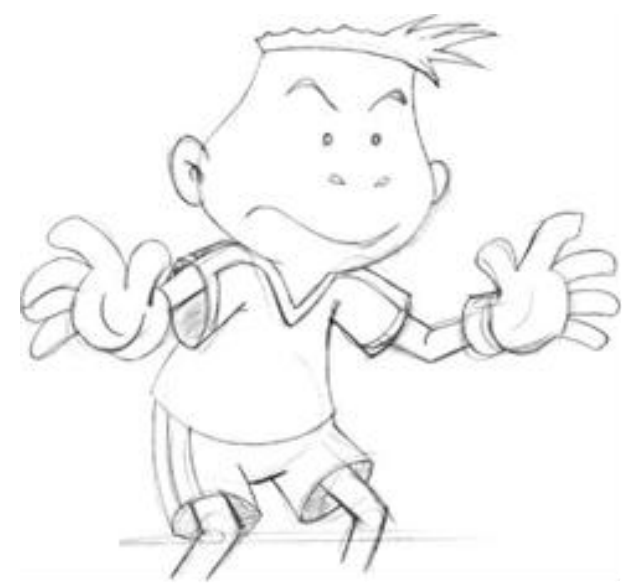

Fig. 1. Goalkeeping Posture

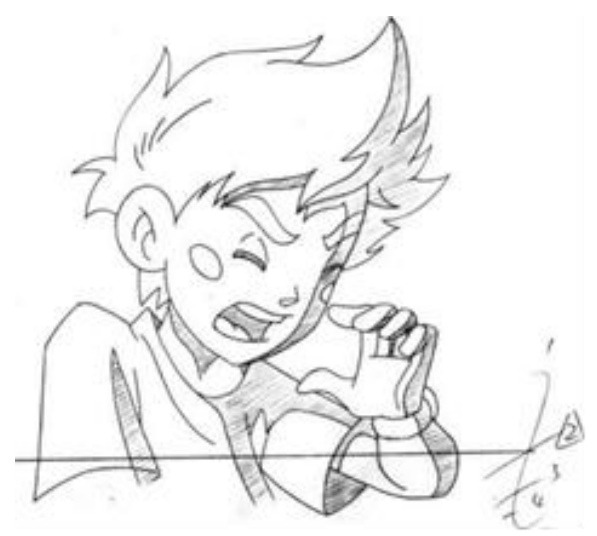

Fig. 2. Expression and Action

\section{DIFFERENCES BETWEEN KEY ANIMATION AND ANIMATION}

Many people may wonder the function of animation and key animation and their differences in the production of cartoon. What's more, both the animation and key animation are different from films acted by real people. Instead of acting by real people, they are created by painters with their paintbrush and wisdom. They give lives to the quite things on the screen. By this way, painters are both the creator and actor of animation and key animation.

Actually, animation and key animation are different from each other. Dating back to the 1920s, there was no animation, let alone animators. All the action paintings in a key animation 
were done by key animator resulting in slow speed in completing the work, but excellent key animator. In this circumstance, many key animators began to find assistants to help them paint inbetweens, so they could have more time to work on key animation and then it could be finished three times earlier than the original. Eventually, these assistants become animators and then the inbetweens by them are now known as animations.

As we can see in "Fig. 3", when there was no assistant which later became animator, all the rolling actions from 1 to 7 were done by key animator. But when there were assistants, they were supposed to paint from 2 to 6 , so the key animators only needed to do with 1 and 7 . Finally, the transitional actions' painting finished by these assistants became animation.
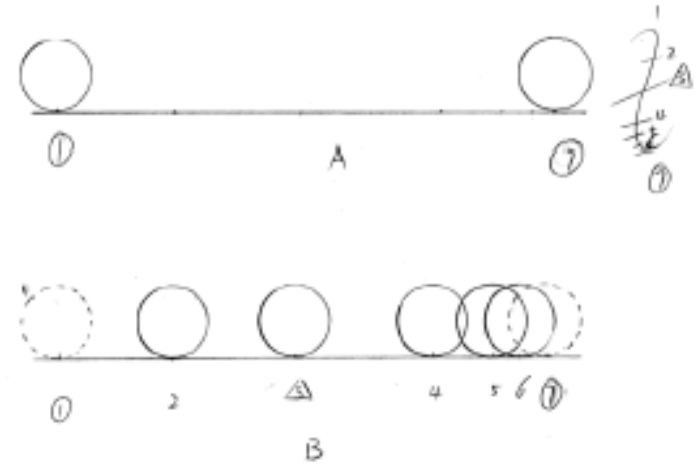

Fig. 3. Key Animation and Inbetweens

Therefore, animators are the assistants and cooperators of key animators and their main task is to give expression to every transitional action in line with the law of motion and principle of key animation.

In a word, animation is a kind of painting that express gradual change of moving objects.

In order to complete the work of a cartoon, recreation of consecutive actions by key animator and animators is necessary and closely related to each other. So only by the cooperation them, can the work be completed successfully.

In this case, a great key animator with a good animator can produce a successful work in the end. "Fig. 4".

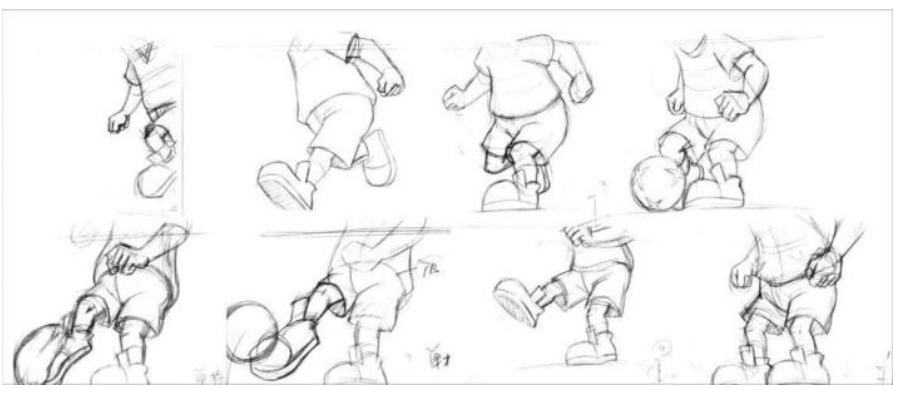

Fig. 4. Ball-kicking Key Animation Draft

\section{THE REQUIREMENTS AND QUALITIES FOR BEING A GREAT KEY ANIMATOR}

As the main drawing person, key animator may need to deal with script of different themes and characters and painting art in different styles. So what are the requirements and qualities for being a successful key animator? How can a key animator be qualified to do such complex work?

\section{A. High Painting Skills and Expressive Ability}

People with great knowledge of art and imagination might not be a great key animator, because the producing of key animation is particular. Key animation designer should paint things just like the real ones, so good knowledge of painting is needed. But there are some key animators who can do well in imagination; however, when they are painting, they cannot express in the way they have imaged even after repeated modification. Because of the strange characters and structure, they have to change their mind or deal with it roughly, which will result in low quality of the cartoon in the end. So in order to improve the ability of painting, a key animator need to carry a sketchbook all the time, and try to do sketching, imitating and memorial painting anytime and anywhere. What's more, instead of solely relying on the training and guidance of teachers in class, students should create animation drafts and decorative paintings by themselves, which is the best way to improve their ability of painting and innovation.

\section{B. Great Imagination Ability}

Besides high painting skills and expressive ability, key animators are supposed to be good at imagination. Cartoon is a kind of artistic creation based on virtuality, romance, exaggeration and imagination, instead of copy of real lives. So being imaginative is the main factor for producing key animation.

Imagination is certainly not fabricated, while it comes from the observation of lives and great knowledge reserves. What's more, the observation should be professional and should be based on careful learning, thinking and analyzing. In this way, instead of being empty in mind, the key animator can choose certain materials in their mind freely. In the end, actions in the film with animated characteristics will become vivid.

\section{Extensive Knowledge and Comprehensive Art Cultivation}

People cannot have enough art knowledge and high art cultivation by chance. Besides the knowledge they can learn from class, students majoring in animation should also pay attention to all things they can get from daily life. It is of great importance for people who are working on key animations to learn knowledge and apply it properly. There are many things can help the creating of key animation in games, for example, literatures of different themes, from which knowledge about imagination of outer space, fairy tales, folklores, depiction of personality, people's inner life, appearance, manner and movement can be learned. As a key animator, one should also be familiar with opera, folk art, dance, martial art, music, photography, history, technology, nature, astronomy and geography. In this way, the appreciation ability and art 
cultivation can be improved and great animations can be produced.

\section{Persistence in the Creation of Key Animations}

Long time is needed for the production of cartoon. What's more, it requires efforts and patience to finish the work. Without enthusiasm and patience, great work can't be produced, so the animator should be professional. People working on animations are in favor of this industry, which results in their professionalism and qualification. Persistence which is a quality of workers in animation industry can be accumulated from learning and practicing and it is necessary for the development of these workers.

\section{E. Teamwork Spirit}

Cartoon is an art based on teamwork. It is different from ordinary paintings and other designs which can be finished by individuals. Cartoons are produced with good designs and by high technology. Many people's efforts are needed from playwriting, script to design of key animation and animation, modeling and rendering as well. All the departments involved are related to each other. Meanwhile, they should follow the requirement of directors, script designs and working procedure. What's more, all the workers are closely coordinated. Cartoon is a special kind of "flow line" art, in which cooperation is of great importance. The designers should not only help the expression of characters, but also provide performance in line with certain rules. Any inharmonious and uncooperative thing is forbidden in its manufacture. In this case, great production can be produced in short time.

In conclusion, animation art is comprehensive. The models of producing animation are applied, but the detail of performance, experience on creation and performing art have been shared as well. To the key animation designers, they have devoted their lives to animation industry, and also have given assistance and inspiration to the following generations.

\section{REFERENCES}

[1] Wang Liai, Wang Zhicheng. Animation Techniques [M]. Hunan: Hunan University Press 2008.12.

[2] Cao Tianquan, Wu Zhen. Key Animation Design [M] .Shanghai: Shanghai People's Fine Arts Publishing House, 2008.3.

[3] Gujie, Key Animation Design [M] . Beijing: The Publishing House of Ordnance Industry, 2013.7. 